\title{
CORRECTION
}

\section{Correction to: Identifying Subgroups of Toddlers with DSM-5 Autism Spectrum Disorder Based on Core Symptoms}

\author{
Holly K. Harris ${ }^{1,2}$ (D) Collin Lee ${ }^{1} \cdot$ Georgios D. Sideridis ${ }^{1} \cdot$ William J. Barbaresi $^{1} \cdot$ Elizabeth Harstad $^{1}$
}

Published online: 8 March 2021

(c) Springer Science+Business Media, LLC, part of Springer Nature 2021

\section{Correction to:}

\section{Journal of Autism and Developmental Disorders} https://doi.org/10.1007/s10803-021-04879-z

The original version of the article has mistakes in Table 7.

The values are in the wrong columns.

The corrected Table 7 is given below.

\section{Elizabeth Harstad}

Elizabeth.harstad@childrens.harvard.edu

1 Division of Developmental Medicine, Massachusetts and Harvard Medical School, Boston Children's Hospital, Fegan 10, 300 Longwood Avenue, Boston, MA 02115, USA

2 Present Address: Department of Pediatrics, Baylor College of Medicine and Meyer Center for Developmental Pediatrics, Texas Children's Hospital, Houston, TX, USA 
Table 7 Alignment of other domains of functioning and demographics on Restricted and Repetitive Behavior Classes

\begin{tabular}{lcll}
\hline Variable & Class 1 & Class 2 & T-test/Chi-square \\
\hline Bayley cognitive & 82.03 & 78.17 & $2.877^{*}$ \\
Vineland communication & 72.86 & 68.63 & $3.531^{*}$ \\
Vineland social & 74.69 & 74.51 & 0.219 \\
Vineland daily living & 79.60 & 75.42 & $3.608^{*}$ \\
Vineland adaptive & 75.79 & 72.70 & $3.405^{*}$ \\
Vineland motor & 87.17 & 85.09 & $2.029^{*}$ \\
Age at visit (months) & 26.68 & 24.83 & $4.60^{*}$ \\
Males & $82.20 \%$ & $74.10 \%$ & $4.720^{*}$ \\
Income & & & 2.247 \\
Low & $2.60 \%$ & $2.20 \%$ & \\
Moderate & $13.50 \%$ & $12.30 \%$ & \\
Middle & $38.50 \%$ & $33.00 \%$ & \\
Upper & $45.50 \%$ & $52.50 \%$ & \\
\hline
\end{tabular}

$* p<.05$.

Publisher's Note Springer Nature remains neutral with regard to jurisdictional claims in published maps and institutional affiliations. 